\title{
"Da Igreja à luta": trajetórias políticas de mulheres agricultoras do Sudoeste do Paraná
}

\author{
Aline Maiara Demétrio Santos' (iD 0000-0002-6953-476X \\ Josiane Carine Wedig ${ }^{2}$ (i) 0000-0003-4569-6956 \\ Hieda Maria Pagliosa Corona' (10) 0000-0003-1790-5423
}

'Universidade Tecnológica Federal do Paraná, Programa de Pós-Graduação em Desenvolvimento Regional, Pato Branco, PR, Brasil. 85503-390 - ppgdr-pb@utfpr.edu.br 2Universidade Tecnológica Federal do Paraná, Departamento de Ciências Humanas e Programa de Pós-Graduação em Desenvolvimento Regional Pato Branco, PR, Brasil. 85503-390 - dahum-pb@utfpr.edu.br

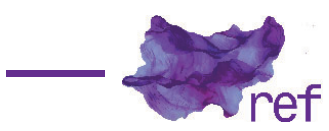

Resumo: Neste artigo, analisamos as trajetórias de mulheres agricultoras no Sudoeste do Paraná a partir das questões de gênero, da formação religiosa e da ação política que implicaram diretamente o exercício de suas lideranças na igreja, no sindicato, em associações, em partido político e em movimentos sociais. Em suas narrativas, constatamos que suas vivências se cruzam com as experiências coletivas das mulheres do campo e das lutas políticas em âmbito regional e nacional. Observamos, também, como essas lideranças foram constituídas e como elas reconfiguram papéis sociais naturalizados enquanto agricultoras. Compreender a trajetória vivenciada por essas mulheres remetenos à questão da interseccionalidade, em que o gênero não tem referentes fixos, mas é marcado pelas diferenças de classe, origem étnica e racial, modo de vida, situação rural e experiência histórica. Palavras-chave: mulheres agricultoras; liderança política; gênero; interseccionalidade.

"From Church to Struggle": Political Trajectories of Peasant Women in Southwest Paraná Abstract: In this article, we analyze the trajectories of women farmers in the Southwest of Paraná based on gender issues, religious formation and political action that directly implied the exercise of their leadership in the church, the union, associations, political parties and social movements. In their narratives, we find that their experiences intersect with the collective experiences of rural women and political struggles at regional and national levels. We also observe how these leaders were formed and how they reconfigure naturalized social roles as farmers. Understanding the trajectory experienced by these women brings us to the question of intersectionality, in which gender has no fixed referents, but is marked by differences in class, ethnic and racial origin, way of life, rural situation and historical experience.

Keywords: Peasant Women; Political Leaders; Gender; Intersectionality.

\begin{abstract}
"De la Iglesia a la lucha": trayectorias políticas de mujeres agricultoras en el suroeste de Paraná"

Resumen: En este artículo analizamos las trayectorias de las campesinas del suroeste de Paraná con base en cuestiones de género, formación religiosa y acción política que implicó directamente el ejercicio de su liderazgo en la iglesia, el sindicato, asociaciones, partidos políticos y movimientos sociales. En sus narrativas, encontramos que sus experiencias se cruzan con las experiencias colectivas de las mujeres rurales y las luchas políticas a nivel regional y nacional. También observamos cómo se formaron estos líderes y cómo reconfiguran los roles sociales naturalizados como agricultores. Entender la trayectoria vivida por estas mujeres nos lleva a la cuestión de la interseccionalidad, en la que el género no tiene referentes fijos, sino que está marcado por diferencias de clase, origen étnico y racial, forma de vida, situación rural y vivencia histórica.
\end{abstract}

Palabras clave: mujeres agricultoras; liderazgo politico; género; interseccionalidad. 


\section{Introdução}

Neste artigo, temos como objetivo analisar as trajetórias de duas mulheres agricultoras ${ }^{1}$ que se tornaram lideranças políticas e referência das lutas da agricultura familiar na região Sudoeste do Paraná: Luciana Guzella Rafagnin e Zelide Cattelan Possamai. No exercício de suas lideranças, é possível observar uma articulação de suas vivências pessoais com as experiências coletivas de outras mulheres, e essa conexão é fundamental para compreender suas trajetórias políticas.

Para analisar essas trajetórias, utilizamos como fonte de pesquisa as narrativas dessas mulheres, em que suas histórias, quando contadas, podem ser lidas a partir da experiência e da memória (Walter BENJAMIN, 1994). As narrativas são relevantes nos estudos de gênero, pois permitem considerar a vida, as atividades e os sentimentos das pessoas, auxiliando na compreensão do passado e do presente. Conforme Maria Lúcia Rocha-Coutinho (2006, p. 67), ao narrar, "as pessoas constroem identidades, articulam suas experiências e refletem sobre o significado destas experiências para si".

Margareth Rago (2013), ao escrever biografias de mulheres feministas brasileiras, considera que as narrativas de si reconstroem o próprio passado, avaliam as experiências vividas e dão sentido ao presente. Além disso, a autora evidencia que tais práticas discursivas são perpassadas por interpretações pessoais dos processos históricos vividos, marcadas pela "memória emblemática", conceito desenvolvido por Steve Stern (2000), que aponta para o cruzamento entre narrativas da transformação de si e da mudança social, misturando as memórias pessoais com as coletivas e públicas.

A pesquisa acerca das experiências dos sujeitos é essencial para a compreensão e o reconhecimento de processos sociais que vão para além dos indivíduos, interconectandoos com os coletivos (Adriana PISCITELLI, 1993). Apesar de existirem questionamentos frente à noção de verdade nas narrativas dos sujeitos, a articulação da experiência com a subjetividade propõe um espaço valioso de interpretações. Esse aspecto pode ser percebido na pesquisa de Maria Ignez Paulilo e Cristiani da Silva (2016, p. 302), ao analisarem as memórias de Luci Choinacki, em que elas propõem que uma trajetória não significa um conjunto coerente e linear de acontecimentos, mas sim uma narrativa que "constrói e reelabora percursos, imagens e representações de si e de eventos que se desviam e se deslocam a todo o momento".

Ao dialogar com as trajetórias políticas das duas mulheres agricultoras em nossa pesquisa, partimos da indicação de Donna Haraway (1995) sobre a relevância da perspectiva parcial e do saber localizado. A escolha das interlocutoras foi orientada no sentido de ouvir mulheres que ocuparam e ocupam espaços políticos relevantes, conquistados em suas trajetórias na agricultura familiar da região Sudoeste do Paraná.

A pesquisa de campo foi desenvolvida entre maio de 2017 e novembro de $2018 .^{2}$ Foram efetuadas três entrevistas semiestruturadas com cada uma das lideranças, realizadas em suas casas e no Sindicato dos Trabalhadores Rurais (STR), no município de Francisco Beltrão, Paraná. Essas diferentes espacialidades foram escolhidas a fim de que as conversas pudessem ativar memórias ligadas a elas. As entrevistas foram gravadas e, posteriormente, transcritas. Além disso, efetuamos observação participante em espaços coletivos das mulheres agricultoras, como reuniões, palestras e atos públicos.

Este artigo está organizado em três seções, além desta introdução e das considerações finais. Na primeira seção, analisamos as vivências de nossas interlocutoras na agricultura familiar e o modo como Zelide e Luciana se constituíram enquanto lideranças políticas, passando pela Igreja Católica, pelo STR e pelo Partido dos Trabalhadores (PT). A partir de suas narrativas, é possível estabelecer relações com os acontecimentos históricos nacionais - como as lutas das mulheres agricultoras durante a Constituinte, nos anos de 1980. Na seção seguinte, abordamos as lutas por terra de famílias agricultoras, no Sudoeste do Paraná (desde os anos de 1950), e a atuação posterior da Teologia da Libertação, como influências significativas para as mobilizações sindicais. Por fim, na terceira seção, discutimos como as dinâmicas de representação política são permeadas por questões interseccionais de gênero, raça, classe e outras, constituindo marcadores sociais que atravessam a experiência de nossas interlocutoras.

\section{As memórias pessoais e as histórias coletivas}

Luciana e Zelide narram suas histórias de vida, durante nossos frequentes encontros, em suas casas, no sindicato e em outros espaços da agricultura familiar. Suas narrativas, em muitos

1 A escolha do termo mulheres agricultoras deve-se ao fato de que Luciana e Zelide assim se identificam. Em outros momentos, aparece o termo camponês/camponesas porque é o modo como as autoras que estão sendo mobilizadas nomeiam.

2 O estudo foi aprovado pelo Comitê de Ética em Pesquisa (CEP) e teve o Termo de Consentimento Livre e Esclarecido (TCLE) assinado pelas interlocutoras, que concordaram que seus nomes fossem utilizados na divulgação acadêmica. A pesquisa é parte da dissertação de mestrado da primeira autora, realizada no Programa de Pós-Graduação em Desenvolvimento Regional da Universidade Tecnológica Federal do Paraná (PPGDR/UTFPR), associada ao grupo de pesquisa do CNPq Gênero, Juventude e Cartografias da Diferença. 
momentos, misturam as memórias de suas trajetórias pessoais com as vivências e os percursos de outras agricultoras e agricultores. Elas falam de si e de suas experiências de vida na região e em suas comunidades locais, mencionam fatos ocorridos no país - explicitando suas participações, como no caso da vivência da Constituinte, para reivindicar direitos e o reconhecimento das mulheres agricultoras.

Luciana nasceu em Mariano Mouro, no Rio Grande do Sul, no ano de 1965, e quando completou três anos de idade sua família foi morar no município de Francisco Beltrão. Nasceu no meio rural, assim como seus pais, que também foram agricultores. A sociabilidade dela, quando criança, foi permeada pela vida na roça e pelos encontros na Igreja Católica - organização que ocupa um lugar central nas vivências das famílias agricultoras da região. Foi na juventude que passou a atuar como liderança na igreja da comunidade em que morava. Posteriormente, passou a fazer parte do STR, fortalecendo-se na militância junto a seu companheiro, que havia conhecido nas jornadas de ação política e religiosa na década de 1980.

Zelide nasceu no ano de 1953, na cidade de Joaçaba, em Santa Catarina, migrando, quando criança, para o município de Francisco Beltrão, em busca de melhores condições de vida. Chegando à região Sudoeste do Paraná, sua família se estabeleceu no espaço urbano, que então se constituía, e só depois de alguns anos foi morar no meio rural. Foi na ida para o campo que Zelide afirma ter se encontrado enquanto agricultora e, nesse espaço, a família obteve melhores condições de vida. A infância de Zelide foi atravessada pela militância sindica de seu pai, um dos primeiros a se associar ao STR, que na época era regional, criado em 1963. Para ela, a liderança e a militância política "devem ser de sangue", referindo-se ao fato de ter seguido os passos do pai, visto que desde pequena o escutava contar sobre as reuniões e lutas sindicais. Também, em seu caso, a Igreja Católica ocupa um lugar importante, tendo sido, desde jovem, muito ativa no meio religioso em sua comunidade, atuando inclusive como catequista e ministra da eucaristia.

Assim, para ambas, o meio religioso foi o espaço no qual se abriram as portas para a militância política, que culminou com a atuação no sindicalismo de trabalhadores rurais, a partir de meados dos anos de 1980, quando se tornaram representantes nas direções, nos cargos de presidência, nas coordenações regionais, na formação de grupos de mulheres, entre outros. Nesses grupos operativos elas passaram a compreender, de maneira crítica, os processos políticos de seu tempo.

Zelide participou ativamente da formação e acompanhamento de grupos nas comunidades rurais, especificamente da Comissão Sindical de Mulheres Agricultoras, cuja organização visava aproximar as mulheres de discussões políticas sobre a necessidade de luta pelos seus direitos. Ela também foi presidente do STR de Francisco Beltrão, por dois mandatos (1993-1996 e 1997-2000), e atualmente participa do Conselho Diretor da Associação de Estudos, Orientação e Assistência Rural (ASSESOAR). ${ }^{3}$

Luciana participou da Coordenação Regional de Mulheres da Federação dos Trabalhadores na Agricultura Familiar (FETRAF), durante a década de 1990, e teve uma atuação expressiva no âmbito político-partidário como filiada do Partido dos Trabalhadores (PT) desde 1989. Ela teve dois mandatos como vereadora do município de Francisco Beltrão (1993-1996; 1997-2000) e quatro como deputada estadual (2001-2002; 2003-2006; 2007-2010; 201 1-2014). ${ }^{4}$ Atualmente, ocupa novo mandato no cargo de deputada estadual (2019-2022).

Ao falarem sobre suas trajetórias políticas, Luciana e Zelide relatam os aspectos que foram constituindo seu percurso, marcado, em muitas ocasiões, por questões de gênero, seja no âmbito familiar e doméstico, seja no espaço público da comunidade rural ou na sociedade de modo mais geral. Enfrentaram discriminações pelo fato de serem mulheres e agricultoras identidades indispensáveis para compreendermos suas trajetórias políticas. Enquanto lideranças, as suas ações estiveram pautadas, particularmente, pelas reivindicações das mulheres e, de modo mais amplo, pela agricultura familiar. Elas se tornaram referência para outras agricultoras, que passaram a se inserir nas mobilizações organizadas pelo STR, pela Igreja Católica e pelo Partido dos Trabalhadores.

Suas trajetórias também estão permeadas pelo período histórico da redemocratização do Brasil, marcado pelas lutas camponesas, que se associavam a outras lutas - como no caso das lutas feministas dos anos 1970, caracterizadas pela contestação à ordem política instituída no País com a Ditadura Militar, iniciada em 1964 (Cynthia SARTI, 2004). Cabe salientar que, nos anos de 1980, as mulheres agricultoras, em todo o País, criaram organizações e movimentos sociais para reivindicar o seu reconhecimento enquanto agricultoras, o acesso a direitos trabalhistas - como aposentadoria, licença-maternidade, auxílio-doença -, o direito à sindicalização e à

\footnotetext{
${ }^{3}$ Agremiação dirigida por agricultoras e agricultores familiares, fundada em 1966, com o apoio de padres belgas e da Congregação dos Sacerdotes do Sagrado Coração de Jesus, e que tem ałuação significativa no apoio às organizações e aos movimentos sociais rurais da região.

4 Em seu primeiro mandato como deputada federal em 2001, Luciana era suplente de Péricles Holleben Mello, que na época havia vencido a eleição para o cargo de prefeito em Ponta Grossa (PR).
} 
titulação conjunta dos lotes na política de reforma agrária, o acesso ao crédito específico para elas e passaram a denunciar as situações de violência doméstica e estrutural às quais estavam expostas.

As organizações de mulheres agricultoras foram apoiadas pelas Comunidades Eclesiais de Base (CEBs) - e pela Comissão Pastoral da Terra (CPT), ${ }^{5}$ passando a questionar as injustiças sociais e de gênero (Carmen Diana DEERE, 2004). Conforme Sarti (2004), os movimentos de mulheres no Brasil se organizaram mais intensivamente nos anos de 1970 e constituíram um importante foco de oposição ao regime militar. As primeiras aparições públicas dos movimentos de mulheres agricultoras ocorreram a partir de marchas a Braślia - já na década de 1980 -, para pressionar a Assembleia Nacional Constituinte, acompanhadas de abaixo-assinados reivindicando o acesso a direitos (Emma SILIPRANDI, 2011). Durante o período da Constituinte, elas passaram a realizar reivindicações no plano das políticas públicas e também reflexões sobre o lugar social das mulheres (SARTI, 2004).

As vivências de Zelide e Luciana, enquanto representantes de agricultoras familiares, também se estenderam para essas lutas no âmbito nacional, por meio de ações coletivas com mulheres de outros estados. Elas relatam que suas viagens ao Distrito Federal foram marcadas por acampamentos, em frente ao Congresso Nacional, e pela construção coletiva de projetos políticos para as mulheres agricultoras e demais trabalhadores rurais. Conforme nos conta Luciana:

Foi então que começamos essa reivindicação... Primeiro para a questão da aposentadoria, pelo direito da aposentadoria, de 55 anos para a mulher e 60 para o homem. Nós levávamos essa luta junto. Não era só da mulher, era do homem e da mulher, e era o direito a um salário mínimo [...] Porque na época era meio salário para o homem e nenhum para a mulher. Junto com isso nós tivemos a luta da licença-maternidade, que também a mulher agricultora não tinha. Então quando conseguimos fazer passar na Constituição esse direito, isso nos deu muita força na questão da organização das mulheres e então isso facilitou muito a vinda das mulheres para essa luta [...] (Luciana G. Rafagnin, entrevista cedida em 17 de maio de 2018).

Por meio da promulgação da Constituição de 1988, as mulheres conquistaram reconhecimento enquanto agricultoras (antes disso, eram nominadas como "do lar", "donas de casa" ou "domésticas"). Para elas também foi sancionado o direito à propriedade da terra, ao seguro desemprego, à aposentadoria por invalidez, à licença-maternidade remunerada e à idade para aposentadoria, estipulada em 55 anos, ou após 30 anos de serviço, na condição de seguradas especiais. A conquista da igualdade formal, contudo, não significou que os direitos conquistados tenham sido imediatamente implantados e assegurados. A sua regulamentação e efetivação dependeu de um conjunto de muitas outras manifestações e ações coletivas das mulheres agricultoras (SILIPRANDI, 2011). Sobre a luta pelo reconhecimento desses direitos e a dificuldade de implementá-los, Zelide refere que:

Eu comecei com a campanha de sindicalização e aí quando terminou, em 1988, foi a época que entrou para a Constituição que a gente teria o direito ao salário-maternidade, à previdência... Aí a gente diz: "Bom, mas tá ali na Constituição, mas e quando que vai valer isso? Temos que ir para luta". [...] O bloco do produtor rural era para a família, e pedíamos para que colocassem o nome do homem e da mulher. Aqui mesmo em Francisco Beltrão, tivemos que ir lá, fazer uma manifestação na frente da prefeitura para que fosse registrado o nome da mulher no bloco (Zelide C. Possamai, entrevista cedida em 08 de junho de 2018).

Nesse sentido, mesmo após a conquista de diversos direitos, "as leis ficavam somente no papel" e as mulheres agricultoras precisaram se mobilizar para concretizá-las. Zelide e Luciana afirmam que a obtenção da aposentadoria e do salário maternidade foram conquistas importantes e tornaram possível o reconhecimento das trabalhadoras rurais. Tais conquistas foram dando mais espaço para que a organização das mulheres pudesse avançar. Após 1988, as mobilizações estavam mais orientadas para a conjuntura local e regional, na cobrança da execução de seus direitos na prática.

As ações coletivas e vivências de sua representatividade são relatadas pelas interlocutoras por meio de percepções que refletem sensações ora de medo, ora de coragem, frente aos desafios que Ihes eram demandados. Luciana, ao relatar a sua atuação junto aos coletivos de mulheres agricultoras, durante os anos 1980 e 1990, menciona que elas a estimularam a se tornar candidata à vereadora:

Como eu organizava as mulheres e falava da importância da participação da mulher, seja no campo econômico, político e social, elas comentavam muito que era um momento de participar e que elas gostariam muito que eu participasse, que eu disputasse as eleições. Eu falo sempre que aquele momento foi um mês quase que eu não dormia, porque eu gostava da política, eu gostava de fazer campanha, mas para os outros! (risos) [...] Era uma coisa assim, eu falo sempre, que nós mulheres pensamos muito antes de dar uma resposta. E eu tinha muito

${ }^{5}$ A CPT foi criada em 1975, com o apoio de alguns segmentos da Igreja Católica, em resposta ao Golpe Militar e em defesa dos trabalhadores do campo. 
medo, fiquei assustada com aquilo e eu falava: 'não, eu não vou', e ao mesmo tempo eu sentia as mulheres falando: 'poxa, você fala para gente ir, agora a gente está pedindo para você ir e você não quer ir' (Luciana G. Rafagnin, entrevista cedida em 17 de maio de 2018).

Na fala de Luciana se percebe que, apesar de seu engajamento político local com as mulheres agricultoras, enquanto liderança, havia uma barreira a ser enfrentada para a sua representação no espaço institucional do Estado, convencionalmente masculino. Isso se deve ao fato de que a representação política nas instituições modernas, nos espaços públicos, foi constituída como estritamente masculina e as mulheres, em grande medida, ficaram restritas ao espaço doméstico (Silvia FEDERICl, 2017).

O relato de Zelide aponta para as barreiras que precisou transpor para se sentir apta a ocupar o espaço público e ter coragem para falar nos meios de comunicação regionais:

Eu tinha um pouco de vergonha, porque nós [descendentes de] italianos temos um sotaque, um sotaque de italiano, de puxar os r's e eu lembro que um dia eles me chamaram para fazer uma entrevista para a rádio de Pato Branco e eu disse que não queria ir porque eu pronuncio as palavras meio ['erradas']. E aí o cara disse assim: "Olha, se vem uma pessoa italiana aqui, ela tem um sotaque, se vem um estrangeiro, ele tem o sotaque dele, se vem uma alemã... Cada um tem o seu". Sabe que depois daquilo eu disse: "Sabe que é mesmo? Não interessa". E fui, dei a entrevista [...] Aquela história do machismo também não me parou... Não afetava tanto, sabe? Ficava um pouquinho na hora ali, mas, ah... Se nós queremos resolver isso aqui, a gente tem que encarar (Zelide C. Possamai, entrevista cedida em 12 de julho de 2018).

Zelide menciona a barreira da língua, mas também seu receio de falar em público - em um meio de comunicação de massa como o rádio -, embaraço que pode estar associado ao fato de ser mulher, agricultora, com uma determinada origem étnica e um modo de vida rural. Desafiar-se a falar em público passou por reconhecer a sua posicionalidade, considerando a legitimidade de sua fala, visto "que todo ato de fala é uma fala de algum lugar" (Lila ABULUGHOD, 2018, p. 197).

Assim, a partir dos relatos de Luciana e Zelide, podemos perceber a representatividade atravessada por questões de gênero, tanto em suas experiências individuais quanto na história coletiva de mulheres agricultoras que adentram o campo político e o espaço público. O processo de representação possui, para elas, uma carga diferenciada em relação aos homens, visto que o perfil de lideranças políticas (sejam elas nos meios partidários, institucionais, organizativos etc.), aliado às atividades que demandam uma exposição pública (campanhas eleitorais, entrevistas em meios de comunicação, discursos públicos, entre outros), compõem práticas naturalizadas do universo masculino. Isso ocorre porque as instituições modernas foram constituídas como espacialidades de homens, brancos, cristãos, heterossexuais, que se autodefiniram como seres de razão, civilizados, ordenadores e governadores do espaço público e como representantes do Estado, da Ciência, do Judiciário, da Medicina, entre outras (María LUGONES, 2008).

Dessa forma, observa-se que essas mulheres se (re)constroem a cada experiência, no exercício da representatividade/liderança em espaços públicos, transformando a si mesmas e ressignificando suas identidades. A participação delas nesses espaços permite transpor o espaço doméstico, propiciando a emergência de uma nova agente política, ao questionar a condição das mulheres e a identidade de gênero (SARTI, 2004).

Apesar dos avanços em termos de políticas formais, há uma série de dificuldades enfrentadas pelas mulheres tanto na vida cotidiana quanto na vida pública. No caso do trabalho realizado pelas mulheres camponesas, ele ainda é invisibilizado e, em diferentes contextos, tem sido visto apenas como ajuda ou trabalho leve (PAULILO, 1987), restrito, em grande medida, ao espaço doméstico. No caso da representação pública - nos bancos, nas cooperativas, nos sindicatos etc. -, ela é, em geral, exercida pelo homem/pai/marido, que é considerado o chefe da família, o produtor rural, e nele se concentra também o controle da renda familiar. Os processos de modernização e industrialização da agricultura, que se intensificaram após a ll Guerra Mundial, com a Revolução Verde, invisibilizaram ainda mais o trabalho realizado pelas mulheres, visto este estar ligado, principalmente, ao autoconsumo da família e ser considerado menos importante que as lavouras comerciais, sob a responsabilidade dos homens (SILIPRANDI, 2011).

É esse conjunto de questões que relaciona as trajetórias políticas das mulheres agricultoras do Sudoeste do Paraná com as lutas mais gerais no âmbito regional e nacional. Pelas narrativas de Zelide e Luciana, observamos que ao mesmo tempo que elas relatam as suas próprias histórias, também estão narrando as experiências coletivas de outras mulheres e os acontecimentos históricos do País. Na seção seguinte, analisamos como essas vivências estão permeadas pelas lutas por terra de famílias agricultoras, desde os anos de 1950, no Sudoeste do Paraná. Além disso, abordamos a relação entre a formação política e religiosa delas na lgreja Católica, principalmente por meio da Teologia da Libertação, evidenciando as influências que essas experiências tiveram na constituição delas enquanto lideranças sindicais. 


\section{"Estávamos saindo da igreja para ir à luta": religião e sindicalismo}

Para compreender as lutas das mulheres agricultoras no Sudoeste do Paraná, é fundamental apresentar, brevemente, o histórico de resistências políticas ocorridas na região, que remontam à Revolta das/os Posseiras/os, nos anos de 1950, ocasionada pela disputa pela terra. A luta das famílias agricultoras foi contra grandes empresas colonizadoras, como a Clevelândia Industrial Territorial Ltda. (CITLA), que se apropriaram de terras da região, com o apoio do governo estadual de Moysés Lupion. Depois de inúmeros enfrentamentos, foi em outubro de 1957, após um conflito aberto, que conseguiram o direito de posse oficial de suas terras, que foram regularizadas apenas a partir de 1961, por meio do Grupo Executivo para as Terras do Sudoeste do Paraná (GETSOP), órgão ligado aos governos federal e estadual (Elir BATTISTI, 2006).

Após esse acontecimento, surgiram diversas entidades e movimentos sociais que construíram espaços políticos engajados às lutas do campo. Dentre elas, em 1963, foi fundado o STR, no município de Francisco Beltrão, enquanto sindicato regional, com 504 sócios, e com o público majoritário masculino, sendo que das 108 assinaturas obtidas para a sua fundação, havia o endosso de apenas uma mulher. A formação desse sindicato teve grande influência da Igreja Católica (Aline SCHMITZ; Patrícia FERNANDES; Roselí SANTOS, 2012).

A Igreja Católica está presente de forma intensa no cotidiano de vida das pessoas no meio rural do Sudoeste do Paraná, tanto para as práticas religiosas quanto para as funções de lazer e sociabilidade, principalmente para as mulheres ${ }^{6}$. Santos (2010), ao estudar a organização política das mulheres agricultoras da região, observou que o movimento teve influência e orientação de padres e leigas/os belgas, que chegaram à região na década de 1960, instituindo um trabalho de evangelização e formação política das famílias agricultoras. Foram esses agentes que também apoiaram a construção da ASSESOAR e do STR. Zelide lembra que, quando era criança, havia um padre chamado José Caekelbergh, que ajudou a fundar o sindicato e que sempre dormia na casa de seus pais quando ia fazer as ações e estudos na igreja da comunidade rural em que ela morava.

Essa ação regional da lgreja, junto às famílias agricultoras, está relacionada à criação da vertente da Teologia da Libertação, cuja articulação ocorreu em diversas regiões do Brasil no final dos anos de 1960, a partir da qual a Igreja Católica passou por algumas transformações, em que parte de seus clérigos deixava de ter uma posição conservadora - que marca sua relação colonial com os povos -, passando a atuar em movimentos sociais do campo.

A Teologia da Libertação, por meio das Comunidades Eclesiais de Base (CEBs) e da Comissão Pastoral da Terra (CPT), posicionou-se contrária à Ditadura Militar, e em defesa das/os camponesas/es e das/os sem-terra, apoiando as populações excluídas e oprimidas socialmente, reconhecendo que elas são portadoras da capacidade de transformação social. As ações que realizavam se voltaram à questão agrária do Brasil, marcada pela concentração de extensas áreas de terras nas mãos de poucos proprietários rurais, que excluía, continuamente, significativas parcelas da população rural do direito a terra e ao trabalho, aumentando a vulnerabilidade social e a opressão sobre as famílias camponesas (João STEDILE; Bernardo FERNANDES, 2005). A CPT marcou fortemente a trajetória de Luciana, que narra que sua atuação política se intensificou quando realizou uma viagem com seu companheiro para Teresina, no Piauí, no ano de 1985, em uma missão da Pastoral, por um período de um ano, que foi considerada por ela uma experiência na qual se fortaleceu enquanto liderança.

Valdete Boni $(2004 ; 2012)$ ressalta que a corrente de tendência progressista da Igreja Católica passou a atuar junto às populações camponesas para a construção dos sindicatos de trabalhadoras/es rurais. A autora evidencia que os movimentos sociais de mulheres camponesas, organizados a partir da Igreja, tinham, inicialmente, interesse apenas pela questão da luta de classe e não pela de gênero especificamente.

No Sudoeste do Paraná, a criação da ASSESOAR foi apoiada pela lgreja - como apontamos acima - e essa entidade constituiu-se enquanto um espaço de formação e de organização de base para as mulheres agricultoras e para várias outras organizações e movimentos sociais regionais. Joice Abrão e Santos (2010) demonstram que a ASSESOAR, desde a sua fundação, atuou em comunidades rurais para auxiliar no desenvolvimento econômico e social. Para esse trabalho, formava catequistas e ministros eucarísticos (esses últimos mais atuantes na época de sua fundação, até final da década de 1970). Além disso, houve também a importante contribuição da missionária belga Paula Broeders, que realizou um trabalho com as mulheres agricultoras, por meio da criação do Movimento Popular de Mulheres (MPM), no início de 1980, o qual recebia apoio da Igreja Católica, da ASSESOAR, do STR e do Sindicato dos Comerciários, atuando em 26 municípios da região (SCHMITZ et al., 2010).

De acordo com Boni (2012) - ao estudar o Movimento das Mulheres Camponesas (MMC) em Chapecó -, a influência da Igreja entre as mulheres rurais foi diminuindo na década de

- Pelo censo demográfico de 2010, tal presença é revelada pelo número dos que se declararam católicos em relação ao total da população residente na região - 490.420 de 587.496 (84\%). 
1990, visto que as novas demandas delas passaram a ser relacionadas à saúde e à sexualidade (controle de natalidade, reprodução, métodos contraceptivos etc.) e com a chegada das ideias feministas, houve um distanciamento dos princípios religiosos. Em nosso contexto de pesquisa, Zelide e Luciana, que sempre foram participantes ativas nas atividades religiosas católicas, relataram que ocorreu um certo distanciamento delas da Igreja e que o fator que mais pesou nessa decisão foi a "falta de tempo", pois elas estavam participando intensamente das lutas sindicais, para as quais dedicavam quase todo seu tempo. Zelide, após alguns anos se dividindo entre a presidência do STR e as atividades como ministra da eucaristia, optou por ficar somente no sindicato, pela sobrecarga de tarefas nas duas atividades.

Mesmo distanciando-se da Igreja, a formação religiosa delas foi fundamental para a sua construção enquanto lideranças políticas. Foi a partir dessa organização que elas se tornaram agentes de transformação social, permitindo olhar o mundo e perceber a necessidade da ação em outros espaços, para além das demandas da própria igreja. A opção pelo sindicalismo é ressaltada por Zelide, que aponta para um conjunto de diferenças de ideais existentes entre a atuação na lgreja e no sindicato:

Tinha certa diferença porque você trabalhava na igreja só o habitual, e nós tínhamos que sair um pouco disso. Se falava em 'ação e oração', só que estava mais na oração e você tem que se desligar um pouco disso para ir lutar por aposentadoria, para que as mulheres fossem sindicalizadas e que tivessem documentação. Então foi um desafio grande, sabe? Era um grande choque, para a igreja, e para época. Não estou falando apenas por mim, mas em toda a diocese, estávamos saindo da igreja para ir à luta (Zelide C. Possamai, entrevista cedida em 12 de julho de 2018, grifos nossos).

Mesmo com algumas divergências entre a militância sindical e as práticas religiosas, Zelide menciona que a sua atuação enquanto liderança comunitária, ligada à lgreja, foi importante para articular a participação de outras/os agricultoras e agricultores para as organizações sindicais de trabalhadores rurais na região:

[...] tinha o apoio da igreja, até que um momento a igreja deu uma paradinha, uma desanimada, porque saíam muitas lideranças da igreja para ir para luta. Então deu aquela fracassada. Até uma vez eu questionei um padre e ele disse em tom de brincadeira: 'vocês estão tirando todos os nossos ministros para ir aos sindicatos'. la para o sindicato quem estava mais esclarecido na comunidade, que sabia que tinha que ir para luta, então deu um pouco o choque, mas a igreja sempre se manteve (Zelide C. Possamai, entrevista cedida em 12 de julho de 2018).

Essa saída da Igreja para o engajamento na luta política sindical também pode ser evidenciada em mudanças ocorridas na ASSESOAR. Nesse sentido, Hieda Corona (2003), analisando documentos dessa entidade, verifica que, na década de 1980, ela passa por mudanças em decorrência do período de redemocratização. Na época, os padres e demais agentes que participavam dessa associação optaram por diferentes projetos e partidos políticos, culminando com mudanças na matriz teórico-ideológica da entidade, que passou a ser dirigida pelos movimentos sociais sindicais e dos sem-terra, por meio de concepções do marxismo leninista, da democracia cristã e da social democracia (ASSESOAR, 2001 apud CORONA, 2003).

No caso da organização sindical rural, regulamentada a partir de 1962, ela passou por diferentes fases, que podem ser evidenciadas da seguinte forma: inicialmente, o sindicato assistencialista, seguido pelo combativo, de mobilizações e propositivo (ABRÃO; SANTOS, 2010). A fase assistencialista se estabeleceu desde a década de 1960 até 1983, durante o período da Ditadura Militar, em que os sindicatos se dedicavam aos serviços médicos e odontológicos e aos encaminhamentos previdenciários, em um contexto no qual o governo intervia neles diretamente (Tomé COLETTI, 2005). Já a fase do sindicalismo combativo e de mobilizações teve início juntamente com a criação da CUT, em 1983, e a articulação dos sindicatos dos trabalhadores rurais no ano de 1988, marcados pela participação ativa em diversas reivindicações por direitos. Após o ano de 1993, as ações foram marcadas pela construção e organização da agricultura familiar, constituindo o sindicalismo propositivo (COLETTI, 2005). O novo sindicalismo, que é instituído a partir dos anos de 1980, apresentava inúmeras demandas, possibilitando a aproximação de agricultoras/es com trabalhadoras/es da cidade e uma agenda política articulada aos setores governamentais e institucionais, a qual reivindicava novos projetos de políticas públicas (Arilson FAVARETO, 2006).

Corona (2003) demonstra que os movimentos sindical e associativista, no Sudoeste do Paraná, estabeleceram estratégias em contraposição ao projeto de modernização do campo que se desenvolveu na época dos governos militares, fazendo com que os STRs fossem designados como de oposição à Ditadura Militar e a outros movimentos conservadores. A ASSESOAR também auxiliou as famílias agricultoras a construir estratégias contrárias às ações excludentes de modernização promovidas pelo Estado.

Conforme Abrão e Santos (2010), a participação mais expressiva das mulheres na região se deu a partir do ano de 1984, no qual ocorreram amplas mobilizações nas comunidades rurais 
com o objetivo de elegê-las para as direções sindicais. Zelide conta que o sindicato esteve sem recursos financeiros durante seis anos, o que fez com que as mulheres se mobilizassem em grupos, para que também pudessem se tornar associadas e, assim, contribuir financeiramente e politicamente. Foi a partir dessa mobilização que Zelide se tornou a primeira mulher eleita presidente do STR, em Francisco Beltrão, permanecendo de 1993 até 2000. Cabe salientar que, com a entrada das mulheres no sindicalismo, passam a ser discutidas, além de questões de acesso a terra e direitos trabalhistas, também questões de gênero.

Para ampliar a compreensão das esferas de representação política das mulheres, a seção seguinte aborda a participação delas no âmbito institucional, considerando a perspectiva de análise interseccional que possibilita entender como os marcadores sociais de gênero, raça, classe e outros influenciam nas possibilidades de constituição de lideranças de mulheres agricultoras.

\section{A perspectiva interseccional da representatividade política}

Considerar a questão da representatividade de mulheres, em contextos políticos institucionais ou em movimentos sociais e sindicais, remete-nos à reflexão sobre as identidades de gênero que se constituem a partir das diversas posicionalidades ocupadas pelas mulheres.

Judith Butler (2003) demonstra que é a partir das estruturas da linguagem e da política que se forma o campo do poder que, assim, legitima práticas que naturalizam o modelo heteronormativo e binário de classificação dos sujeitos na sociedade. A autora problematiza a formulação do sujeito do feminismo e das lutas feministas frente a essa questão e propõe que sua tarefa política não é a recusa da representatividade, mas sim a formulação de "[...] uma crítica às categorias de identidade que as estruturas jurídicas contemporâneas engendram, naturalizam e imobilizam" (BUTLER, 2003, p. 22). Ela questiona a categoria mulher como uma identidade comum, e salienta que "se alguém 'é' uma mulher, isso não é tudo que esse alguém é", visto que o gênero estabelece interseções com modalidades de raça, classe, etnia, sexo, região etc., constituindo identidades discursivamente constituídas e não fixas (BUTLER, 2003, p. 20).

Em relação a isso, Piscitelli (2009) evidencia a necessidade de situar as relações de gênero, levando em consideração o espaço/tempo no qual diferentes mulheres estão inseridas, demonstrando que há opressões interseccionais que se apresentam muito diversas em contextos como o "Ocidente", o "Oriente" e o "Terceiro Mundo". A autora exemplifica esse aspecto ao demonstrar a situação desigual da representação política feminina no Brasil, em que aquelas que se tornam lideranças, em geral, possuem altos níveis de educação e de trabalho, ${ }^{7}$ o que aponta para situações desiguais que se interpõem entre mulheres dos segmentos econômicos altos e médios, quando comparadas com aquelas dos baixos segmentos. Desse modo, em diferentes contextos, elas enfrentam diferenciadas formas estruturais de violência e opressão, cujos índices são mais elevados nas camadas sociais negras e pobres.

Cabe salientar que o conceito de interseccionalidade foi elaborado por teóricas do feminismo negro e se difundiu com as análises propostas pela jurista Kimberlé Crenshaw (2002), que demonstrou como o sistema de opressões é múltiplo, simultâneo e complexo e no qual as questões de raça, classe e gênero estão emaranhadas nas discriminações vivenciadas por mulheres negras. Para a autora, a interseccionalidade refere-se ao cruzamento de sistemas discriminatórios que perpetuam as desigualdades que irão estruturar posições sociais e classificações hierárquicas dos sujeitos. É a partir da interseccionalidade que é possível analisar as ações e políticas de opressão, permeadas pela desigualdade estrutural (CRENSHAW, 2002).

O conceito de interseccionalidade, portanto, permite compreender que o gênero não tem referentes fixos, rompendo com o essencialismo da categoria mulher (ou mulheres em termos universalizantes). Nesse sentido, é possível entender que o gênero é marcado por um sistema de diferenças intersectado por outros sistemas de diferenças, como classe, raça, sexualidade, origem étnica, experiência pessoal, idade, modo de vida, saúde, situação urbana ou rural e experiência histórica (Lila ABU-LUGHOD, 2018).

A perspectiva da interseccionalidade nos permite analisar, também, as questões que permeiam a vida de agricultoras que se tornaram lideranças políticas, já que suas especificidades não podem ser identificadas enquanto universais da identidade de gênero. Luciana e Zelide enfrentaram o preconceito e a recusa comunitária ao exercício da sua liderança e representação, pelo fato de serem mulheres, mães e agricultoras - que carregam estigmas relacionados a seus modos de viver, demarcando seu lugar social. No entanto, cabe observar que, mesmo permeadas por esses processos de opressão, elas são mulheres brancas, casadas nos moldes heteronormativos, ligadas à religiosidade católica, com famílias nucleares constituídas, o que lhes dá certo privilégio com relação a outros marcadores raciais, sexuais, religiosos etc.

\footnotetext{
${ }^{7}$ É importante destacar que Luciana e Zelide não se enquadram nessa definição de altos níveis de educação e trabalho, pois concluíram o Ensino Médio com o Supletivo depois de adultas. Luciana formou-se em Ciências Sociais quando já ocupava o cargo de deputada estadual.
} 
Em razão disso, entendemos a importância de considerar a interseccionalidade ao abordar as trajetórias de Luciana e Zelide, pois suas histórias se cruzam, ao mesmo tempo que se diferenciam às de outras mulheres. Ao optar por essa perspectiva de análise, podemos questionar as brechas que se abrem para algumas diferenças interseccionais e entender os limites que ainda se impõem à representação ligada a diferentes marcadores sociais.

Dessa maneira, abordar as suas trajetórias políticas desafia-nos a partir da noção de experiência para entender como suas trajetórias individuais estão cruzadas com as dinâmicas sociais. Elas falam sobre suas experiências de vida e relatam os enfrentamentos que fizeram para se tornarem lideranças e representantes políticas. Zelide conta que, ao exercer a presidência no STR, defrontou-se com diversos obstáculos vindos do público, como as críticas que recebia por ser mulher e a recusa de vários homens em tratar assuntos sindicais com "uma" presidente: O pessoal chegava e perguntava: 'cadê o presidente do sindicato?'. Aí eu dizia: 'Sou eu'. Mas a gente foi superando e conseguimos, na época, fazer um trabalho bem importante nesse reconhecimento das mulheres (Zelide C. Possamai, entrevista cedida em 08 de junho de 2018).

Zelide também recebeu críticas da comunidade rural em que residia, frente às responsabilidades que eram esperadas de uma mulher, agricultora, casada e mãe. Ela menciona que havia percepções distintas sobre sua liderança na comunidade onde viveu desde criança e na qual foi morar após se casar. Na sua comunidade de origem, as pessoas reconheciam sua liderança como positiva e enalteciam sua trajetória; já na comunidade onde ela reside, tal liderança era vista como um impedimento ao trabalho doméstico ou ao cumprimento de suas obrigações como mãe. As pessoas questionavam o seu marido, que apoiava a sua trajetória de liderança: [...] o pessoal perguntava para ele [marido]: 'mas tu deixa sua mulher ficar fora? Tem criança para cuidar!'. E ele dizia: 'mas eu estou cuidando das crianças e estou cuidando bem delas' (Zelide C. Possamai, entrevista cedida em 12 de julho de 2018).

Observamos, nessa narrativa, as dificuldades oriundas da conciliação entre a militância política das mulheres e a naturalização das atividades do âmbito doméstico como exclusivamente femininas. Esse aspecto também foi observado por Giovana Salvaro, Mara Lago e Cristina Wolff (2014) em pesquisa realizada com movimentos sociais de mulheres rurais em Santa Catarina, em que as autoras perceberam que a maior participação política das mulheres na esfera pública entrava em choque com uma organização social familiar que definia o papel da mulher como subordinado ao espaço doméstico.

Luciana explicita o preconceito por ela vivenciado, exercido por pessoas que não aceitavam mulheres na política partidária, tendo ouvido diversas vezes que o lugar dela não era naquele espaço. Nesse, sua liderança foi questionada e muitas vezes era comparada com outros colegas por ser "mulher", por ter "menos voto", por ser "agricultora" ou por integrar "tal partido" (Luciana G. Rafagnin, entrevista cedida em 17 de maio de 2018). Ela relata alguns dos preconceitos enfrentados:

[...] nós sofremos muito preconceito e não só por parte dos homens. Eles falavam: 'ah, o que mulher está fazendo na política?' O que ela vai mudar?' 'O que ela vai se meter na política?' 'Ela tem uma família, ela tem filhos, tem que fazer outra coisa...'. Então isso eu ouvi muitas vezes. Eu acho que a principal discriminação foi nesse sentido, sabe? De acharem que a política não era um espaço de mulher (Luciana G. Rafagnin, entrevista cedida em 17 de maio de 2018).

Para enfrentar essa discriminação, ela obteve o apoio de alguns familiares e de membras de sua comunidade, contudo, outros familiares não entendiam o motivo de ela e de seu companheiro participarem com tanta persistência dos movimentos sociais, sem receberem remuneração para isso.

Essa desaceitação das mulheres rurais em espaços de representação se deve a um estereótipo difundido em diversas regiões, em que o trabalho realizado por elas é visto, exclusivamente, como destinado ao cuidado da casa, das crianças, dos idosos e dos doentes. Além disso, têm a incumbência de preparação da comida, de manejo da horta e dos pequenos animais, atividades focadas na produção para o autoconsumo da família (PAULILO, 2004). Portanto, essas mulheres são desqualificadas para o espaço público, ao se requerer delas a resignação ao espaço doméstico.

Discutir as relações de gênero no contexto político formal implica compreender como essas construções sociais estão arraigadas (Joan SCOTT, 1995). Essa questão é evidenciada na fala de Zelide, quando nos conta sobre como as discussões de gênero adentravam as reuniões do STR, nas quais as questões propostas pelas mulheres eram vistas, pelos homens, de maneira separada daquelas que se referiam às demandas dos trabalhadores e da agricultura familiar:

Começamos a querer trazer os presidentes dos sindicatos para discutir junto e quando se puxava o debate para fazer um trabalho que envolvia gênero, aí o bicho pegava. Era uma discussão! Nós ficávamos muito preocupadas, porque nas reuniões eles propunham uma pauta e mais outra pauta, e o assunto que era ligado a gênero ou mulheres ficava por último, 
para quando todo mundo já estava indo embora (Zelide C. Possamai, entrevista cedida em 08 de junho de 2018).

Nessa narrativa, é possível observar como as questões vinculadas à produção e ao trabalho, para os dirigentes homens, tinham primazia sobre as questões de gênero, que eram deixadas em segundo plano pela direção sindical, mesmo quando as mulheres insistiam que elas fossem abordadas.

A identidade política, enquanto agricultora, é central para a mobilização feita por essas mulheres. Luciana afirma que, apesar de ficar distante da vivência na agricultura desde que se tornou deputada estadual, não deixou de ser agricultora e nem de lutar por esse espaço e pelas mulheres rurais, mesmo que seu foco de atuação e representatividade política tenha sido ampliado:

Depois de 2001, quando eu assumi enquanto deputada, ficamos um pouco distantes da produção de alimentos, mas a luta, o trabalho, as organizações continuaram. Claro que, como deputada, a gente acabou ampliando bastante o nosso círculo de atuação e as lutas se tornaram maiores. Antes nós estávamos mais voltados ao Sindicato dos Trabalhadores Rurais, e depois, às associações, ao MST, ao MAB [Movimento dos Atingidos por Barragens], aos sindicatos urbanos [...] (Luciana G. Rafagnin, entrevista cedida em 17 de maio de 2018).

Luciana se percebe enquanto agricultora, principalmente, por lutar pela questão das/ os trabalhadoras/es rurais e viver ainda hoje no campo, mesmo permanecendo por longos períodos na cidade em razão de suas funções políticas.

Zelide percebe sua identidade enquanto agricultora pela questão da vivência no espaço rural:

Eu não consigo me imaginar morando na cidade. Durante esse tempo que eu trabalhei no sindicato, eu ficava durante a semana lá, mas eu não via a hora de vir pra casa. Eu não consigo me imaginar indo morar na cidade e não ser agricultora (Zelide, entrevista cedida em 8 de junho de 2018).

Stuart Hall (2006, p. 12) demonstra que a construção de um sujeito está marcada pela fragmentação das identidades, tornando-as um aspecto "provisório, variável e problemático". Consideramos, portanto, nesta análise, que a identidade não é um ideal normativo, mas que é constituída e reformulada pela experiência das agricultoras, que ora são fortalecidas e ora enfrentam dificuldades em exercer a representatividade no espaço público. Nesse sentido, ao tornar-se liderança política, essas mulheres enfrentam certos questionamentos acerca de seus modos de vida, de suas supostas responsabilidades, de suas pautas políticas, entre outras.

É possível perceber, de acordo com as vivências de Zelide e Luciana, que, para as mulheres exercerem liderança política, elas precisam, cotidianamente, (re)afirmarem sua posição e a legitimidade de suas práticas, frente a uma sociedade em que o ambiente político institucional é majoritariamente masculino, branco, de classe alta, com diversas formas de opressão contra as mulheres e outros sujeitos com diferentes marcadores interseccionais.

Podemos perceber que as resistências das mulheres agricultoras, que exercem lideranças políticas, estão produzindo rupturas com o modelo patriarcal de poder, por meio da afirmação de suas próprias identidades e da criação de processos de subjetivação no espaço público, reconfigurando esses espaços masculinizados.

\section{Consideraçōes finais}

Neste artigo, analisamos as trajetórias de Luciana e Zelide, considerando como se articulam suas vivências individuais com experiências coletivas de mulheres agricultoras, em aspectos que fizeram parte tanto do histórico dos movimentos sociais do campo na região do Sudoeste do Paraná, como do processo de redemocratização do Brasil, que culminou com a promulgação da Constituição de 1988. Em suas narrativas, evidenciaram memórias do passado, que se tornaram experiências vivas e capazes de fazer rever suas próprias práticas e modos de ser, ao relatarem a si mesmas.

Além disso, a análise a partir da perspectiva interseccional e das identidades políticas, em suas relações com o exercício de representatividade e liderança, foram aspectos relevantes para compreendermos as relações de poder que estão presentes no ambiente político do espaço público. As experiências dessas duas mulheres nos fazem refletir sobre as várias questões que perpassam o 'tornar-se' liderança no meio político institucional, visto que elas tiveram que se desdobrar diante da sobreposição de papéis sociais a elas atribuídos. Muitas vezes suas participações são questionadas, tanto no âmbito privado quanto no público.

Assim, vemos que a representatividade em diferentes espaços pode ser fortalecida ou dificultada, dependendo de como ocorrem as relações sociais e de como emergem os apoios e as pressões. Podemos citar como exemplo a Igreja, que, em alguns momentos, foi um ponto essencial de apoio para o exercício da liderança política e, em outros, dificultou o trabalho concomitante nos sindicatos, pelo excesso de tarefas nessas mobilizações sociais. 
Essas mulheres agricultoras estão engajadas com a tarefa cotidiana de re-fazer e repensar suas práticas, buscando romper com a naturalização dos papéis sociais de gênero e da divisão sexual do trabalho. A representação política não é um espaço atribuído às mulheres e, nesse sentido, quando é exercida por elas, essas acabam enfrentando desigualdades de gênero e de outros aspectos interseccionais. Assim, torna-se necessário resistir, a todo o momento, ao preconceito e às pressões familiares, das entidades, das instituições, para construir um modo de viver contra o hegemônico.

\section{Referências}

ABRÃO, Joice Aparecida Antonello; SANTOS, Roselí Alves dos. "Sindicalismo rural em Francisco Beltrão: a inserção do trabalho das mulheres nos espaços políticos administrativos do sindicato dos trabalhadores rurais". In: FAZENDO GÊNERO, 9, 2010, Florianópolis, UFSC. Anais... Florianópolis: UFSC, 2010. p. 01-10.

ABU-LUGHOD, Lila. "A escrita contra a cultura". Equatorial - Revista do Programa de PósGraduação em Antropologia Social da UFRN, Natal, v. 5, n. 8, p. 193-226, janeiro/junho 2018.

BATTISTI, Elir. "As disputas pela terra no Sudoeste do Paraná". Campo-Território: Revista de Geografia Agrária, Uberlândia, v. 1, n. 2, p. 65-91, agosto 2006.

BENJAMIN, Walter. Magia e técnica, arte e política. São Paulo: Editora Brasiliense, 1994.

BONI, Valdete. "Poder e igualdade: as relações de gênero entre sindicalistas rurais de Chapecó, Santa Catarina". Revista Estudos Feministas, Florianópolis, v. 12, n. 1, p. 289-302, janeiro/abril 2004.

BONI, Valdete. De agricultoras a camponesas: o movimento de mulheres camponesas de Santa Catarina e suas práticas. 2012. Doutorado (Programa de Pós-Graduação em Sociologia Política) - Centro de Filosofia e Ciências Humanas da Universidade Federal de Santa Catarina, Florianópolis, SC, Brasil.

BUTLER, Judith. Problemas de gênero: feminismo e subversão da identidade. Rio de Janeiro: Editora Civilização Brasileira, 2003.

COLETTI, Tomé. Organização da produção na agricultura familiar: análise das proposições do sindicalismo rural cutista do Sul do Brasil. 2005. Monografia (Graduação em Economia) - Centro de Ciências Econômicas da Universidade Federal de Santa Catarina, Florianópolis, SC, Brasil.

CORONA, Hieda Maria Pagliosa. "As estratégias dos agricultores familiares do Sudoeste do Paraná frente à modernização no campo". In: CONGRESSO BRASILEIRO DE SOCIOLOGIA, 11., 2003, Campinas, Unicamp. Anais... Campinas: Unicamp, 2003. p. 01-26.

CRENSHAW, Kimberlé. "Documento para o encontro de especialistas em aspectos da discriminação racial relativos ao gênero". Revista Estudos Feministas, Florianópolis, v. 10, n. 1, p. 171-188, janeiro/abril 2002.

DEERE, Carmen Diana. "Os direitos da mulher a terra e os movimentos sociais rurais na reforma agrária Brasileira". Revista Estudos Feministas, Florianópolis, v. 12, n. 1, p. 175-204, janeiro/abril 2004.

FAVARETO, Arilson Silva da. "Agricultores, trabalhadores: os trinta anos do novo sindicalismo rural no Brasil". Revista Brasileira de Ciências Sociais, São Paulo, v. 21, n. 62, p. 27-44, outubro 2006.

FEDERICI, Silvia. Calibã e a bruxa: mulheres, corpo e acumulação primitiva. São Paulo: Editora Elefante, 2017.

HALL, Stuart. Identidades culturais na pós-modernidade. Rio de Janeiro: Editora DP\&A, 2006.

HARAWAY, Donna. "Saberes localizados: a questão da ciência para o feminismo e o privilégio da perspectiva parcial”. Cadernos Pagu, Campinas, n. 5, p. 7-41, 1995.

LUGONES, María. “Colonialidad y género”. Tabula rasa, Bogotá, n. 9, p. 73-102, julho/dezembro 2008.

PAULILO, Maria Ignez; SILVA, Cristiani Bereta da. "Memórias e trajetórias de Luci Choinack: histórias e lutas pelos direitos das mulheres camponesas". In: PAULILO, Maria Ignez. Mulheres Rurais: quatro décadas de diálogo. Florianópolis: Editora da Universidade Federal de Santa Catarina, 2016. p. 301-326. 
PAULILO, Maria Ignez. "O peso do trabalho leve". Revista Ciência Hoje, Rio de Janeiro, v. 5, n. 28 , p. 64-70, janeiro/fevereiro 1987.

PAULILO, Maria Ignez. "Trabalho familiar: uma categoria esquecida de análise". Revista Estudos Feministas, Florianópolis, v. 12, n. 1, p. 229-252, janeiro/abril 2004.

PISCITELLI, Adriana. "Tradição oral, memória e gênero: um comentário metodológico". Cadernos Pagu, Campinas, n. 1, p. 150-200, janeiro 1993.

PISCITELLI, Adriana. "Gênero: a história de um conceito". In: ALMEIDA, Heloisa Buarque de; SZWAKO, José (Orgs.). Diferenças, igualdade. São Paulo: Editora Berlendis \& Vertecchia, 2009. p. 116-148.

RAGO, Margareth. A aventura de contar-se: feminismos, escrita de si e invenções da subjetividade. Campinas: Editora da Unicamp, 2013.

ROCHA-COUTINHO, Maria Lúcia. "A narrativa oral, a análise de discurso e os estudos de gênero". Estudos de Psicologia, Campinas, v. 11, n. 1, p. 65-69, janeiro/abril 2006.

SALVARO, Giovana Ilka Jacinto; LAGO, Mara Coelho de Souza; WOLFF, Cristina Scheibe. "Limites e possibilidades da militância política em um movimento social rural de mulheres". Revista Estudos Feministas, Florianópolis, v. 22, n. 1, p. 51-70, janeiro/abril 2014.

SANTOS, Roselí Alves dos. "A participação política das mulheres agricultoras nas organizações populares e sindicais no Sudoeste do Paraná". Geo UERJ, Rio de Janeiro, v. 2, n. 21, p. 312-329, janeiro/fevereiro 2010.

SARTI, Cynthia Andersen. "O feminismo brasileiro desde os anos 1970: revisitando uma trajetória". Revista Estudos Feministas, Florianópolis, v. 12, n. 2, p. 35-50, maio/agosto 2004.

SCHMITZ, Aline Motter; FERNANDES, Patrícia Aparecida; SANTOS, Roselí Alves dos. "A participação das mulheres agricultoras no sindicato dos trabalhadores rurais - STR de Francisco Beltrão - PR: uma discussão de gênero na geografia". In: ENCONTRO NACIONAL DE GEOGRAFIA AGRÁRIA, 21, 2012, Uberlândia, Universidade Federal de Uberlândia. Anais... Uberlândia: UFU, 2012. p. 01-21.

SCHMITZ, Aline Motter et al. Registrando a história e as experiências político-organizativas das mulheres agricultoras no Sudoeste Paranaense. Francisco Beltrão: Editora Unioeste, 2010.

SCOTT, Joan. "Gênero: uma categoria útil para os estudos históricos". Educação e Realidade, Porto Alegre, v. 20, n. 2, p. 5-22, julho/dezembro 1995.

SILIPRANDI, Emma. "Mulheres agricultoras no Brasil: sujeitos políticos na luta por soberania e segurança alimentar". Pensamiento Iberoamericano, Espanha, n. 9, p. 169-183, 2011.

STEDILE, João Pedro; FERNANDES, Bernardo Mançano. Brava gente: a trajetória do MST e a luta pela terra no Brasil. São Paulo: Editora Perseu Abramo, 2005.

STERN, Steve. "De la memoria suelta a la memoria emblemática: hacia el recordar y el olvidar como proceso histórico (Chile, 1973-1998)". In: GARCÉS, Mario et al. (Orgs.). Memoria para un nuevo siglo: Chile miradas a la segunda mitad del siglo XX. Santiago: Editora LOM, 2000. p. 11-33.

Aline Maiara Demétrio Santos (alinemdemetrio@gmail.com) é psicóloga, mestre em Desenvolvimento Regional pela Universidade Tecnológica Federal do Paraná e servidora pública no departamento de educação no município de Bom Sucesso do Sul - Paraná.

Josiane Carine Wedig (josiwedig@gmail.com) é bacharel e licenciada em Ciências Sociais pela Universidade Federal de Pelotas, mestre em Desenvolvimento Rural pela Universidade Federal do Rio Grande do Sul, doutora de Ciências Sociais em Desenvolvimento, Agricultura e Sociedade pela Universidade Federal Rural do Rio de Janeiro. Professora de Sociologia da Universidade Tecnológica Federal do Paraná.

Hieda Maria Pagliosa Corona (hiedacorona@hotmail.com) é bacharel e licenciada em Ciências Sociais e mestre em Sociologia pela UFPR, doutora em Meio Ambiente e Desenvolvimento pela UFPR, pós-doutora em Desenvolvimento socioambiental pelo Ladyss/ Paris X e Desenvolvimento Rural pelo PGDR/UFRGS. Professora Permanente e bolsista sênior do Programa de Pós-Graduação em Desenvolvimento Regional (PPGDR/UTFPR). 


\section{COMO CITAR ESTE ARTICO DE ACORDO COM AS NORMAS DA REVISTA}

SANTOS, Aline Maiara Demétrio; WEDIG, Josiane Carine; CORONA, Hieda Maria Pagliosa. "'Da Igreja à luta': trajetórias políiticas de mulheres agricultoras do Sudoeste do Paraná". Revista Estudos Feministas, Florianópolis, v. 29, n. 2, e67222, 2021.

\section{CONTRIBUIÇĀO DE AUTORIA}

Aline Maiara Demétrio Santos: Contribuição na concepção da temática, coleta e análise de dados, elaboração do manuscrito, redação e discussão de resultados.

Josiane Carine Wedig: Contribuição na concepção da temática, elaboração do manuscrito, revisão da redação e discussão de resultados.

Hieda Maria Pagliosa Corona: Contribuição na concepção da temática, elaboração do manuscrito, revisão da redação e discussão de resultados.

\section{FINANCIAMENTO}

Não se aplica.

\section{CONSENTIMENTO DE USO DE IMAGEM}

Não se aplica

\section{APROVAÇÃO DE COMITÊ DE ÉTICA EM PESQUISA}

Este artigo faz parte do projeto de pesquisa intitulado "Trajetórias de mulheres agricultoras líderes políticas no Sudoeste do Paraná: resistências e conquistas". O projeto foi aprovado pelo comitê de ética em pesquisa em 14/04/2018. CAAE: 86816218.9.0000.5547 Parecer: 2598905.

\section{CONFLITO DE INTERESSES}

Não se aplica.

\section{LICENÇA DE USO}

Este artigo está licenciado sob a Licença Creative Commons CC-BY 4.0 International. Com essa licença você pode compartilhar, adaptar, criar para qualquer fim, desde que atribua a autoria da obra.

\section{HISTÓRICO}

\section{Recebido em 25/08/2019}

Reapresentado em 07/09/2020

Aprovado em 01/02/2021 